\title{
Behaviour and body patterns of Octopus vulgaris facing a baited trap: first-capture assessment
}

\author{
Marta Dominguez-Lopez ${ }^{1}$, Guillermo Follana-Berná ${ }^{1}$, Pablo Arechavala-Lopez ${ }^{1,2}$ \\ ${ }^{1}$ Fish Ecology Group, Mediterranean Institute for Advanced Studies - IMEDEA (CSIC/UIB), C/ Miquel Marquès, 21, \\ 07190 Esporles, Spain. \\ (MD-L) E-mail: martad149@ hotmail.com. ORCID iD: https://orcid.org/0000-0003-2383-9856 \\ (GF-B) E-mail: g.follana@ gmail.com. ORCID iD: https://orcid.org/0000-0001-9314-6567 \\ (PA-L) (Corresponding author) E-mail: pablo@ fishethogroup.net. ORCID iD: https://orcid.org/0000-0002-6816-8542 \\ ${ }^{2}$ Fish Ethology and Welfare Group, Centro do Ciencias de Mar (CCMAR), Campus de Gambelas, edificio 7, Universidade \\ do Algarve 8005-139, Faro, Portugal.
}

\begin{abstract}
Summary: This study highlights for the first time individual differences in ethology and vulnerability of Octopus vulgaris (i.e. body postures, movements and skin displays) facing passive baited traps. Common octopus exposed to a baited trap during three consecutive first-capture tests exhibited diverse behavioural and body pattern sequences resembling when the octopus searches for and hunts its wild prey. Overall, they first visually recognized new objects or potential preys and rapidly moved out of the den, exploring, grabbing and approaching the trap with the arms (chemotactile exploration), and capturing the bait with the arms and feeding on top over long periods inside the trap. Simultaneously, O. vulgaris displayed diverse skin textural and chromatic signs, the regular pattern being the most frequent and long-lasting, followed by broad mottle, passing cloud and dark patterns. All individuals $(n=8)$ caught the bait at least once, although only five octopuses $(62.5 \%)$ entered the trap in all three tests. In addition, high variability among individuals was observed regarding behaviour and body patterns during the first-capture tests, which might evidence different individual temperaments or life-history traits. Differences in behavioural responses at individual level might have population consequences due to fisheries-induced selection, although there is a high necessity to assess how behavioural traits might play an important role in life-history traits of this species harvested by small-scale trap fisheries.
\end{abstract}

Keywords: common octopus; skin displays; ethology; personality; vulnerability; fisheries management.

Patrones corporales y conductuales del pulpo Octopus vulgaris frente a nasas con cebo: estudio de la primera captura

Resumen: Este estudio muestra por primera vez las diferencias individuales en cuanto al comportamiento y la vulnerabilidad del pulpo Octopus vulgaris (posturas corporales, movimientos, patrones de piel) frente a las trampas con cebo (nasas). Los pulpos fueron expuestos a una trampa con cebo durante tres pruebas consecutivas para estudiar la primera captura, y exhibieron secuencias comportamentales y patrones corporales que se asemejan a cuando el pulpo busca y caza sus presas en el medio natural. En general, primero reconocen visualmente nuevos objetos o potenciales presas, y rápidamente salen de su refugio, explorando el entorno y acercándose a la trampa, agarrando con los brazos (exploración quimiotáctil), y capturando el cebo con los brazos y alimentándose durante largos períodos dentro de la trampa. Simultáneamente, $O$. vulgaris mostró diversos patrones cromáticos y de textura de la piel, siendo el patrón "regular" el más frecuente y duradero, seguido de amplios patrones moteados, dinámicos y oscuros. Todos los individuos $(\mathrm{n}=8)$ capturaron el cebo al menos una vez, aunque sólo cinco pulpos (62.5\%) entraron en la trampa en las tres pruebas. Además, se observó una gran variabilidad entre los individuos en cuanto al comportamiento y los patrones corporales durante las pruebas de primera captura, lo que podría evidenciar diferentes temperamentos individuales o rasgos de la historia de la vida. Las diferencias en las respuestas conductuales a nivel individual podrían tener consecuencias para la población debido a una selección inducida por la pesca, aunque es necesario evaluar cómo los rasgos conductuales podrían desempeñar un papel importante en el ciclo vital de esta especie, capturada por pescadores artesanales con trampas o nasas.

Palabras clave: pulpo común; patrones de piel; etología; personalidad; vulnerabilidad; gestión pesquera.

Citation/Como citar este artículo: Dominguez-Lopez M., Follana-Berná G., Arechavala-Lopez P. 2021. Behaviour and body patterns of Octopus vulgaris facing a baited trap: first capture assessment. Sci. Mar. 85(1): 29-38. https://doi. org/10.3989/scimar.05065.003

Editor: R. Villanueva.

Received: April 6, 2020. Accepted: October 22, 2020. Published: March 31, 2021.

Copyright: ( $) 2021$ CSIC. This is an open-access article distributed under the terms of the Creative Commons Attribution 4.0 International (CC BY 4.0) License. 


\section{INTRODUCTION}

The common octopus (Octopus vulgaris Cuvier, 1797) is a cephalopod species of high ecological and economic interest worldwide. It is mainly distributed throughout the Mediterranean Sea and in central-eastern Atlantic waters, though morphological and genetic differences have been described among populations in its distribution range (Jereb et al. 2015, De Luca et al. 2016, Amor et al. 2017). $O$. vulgaris is a merobenthic species inhabiting coastal seagrasses and rocky, sandy and muddy bottoms up to $200 \mathrm{~m}$ depth, being most frequently found in coastal waters, even in areas with high anthropic pressure (Katsanevakis and Verriopoulos 2004a, Guerra et al. 2014, Sillero-Rios et al. 2018). It is an important fishery resource that has gained market value in recent decades and is taken throughout the year as a target species in bottom trawls and small-scale coastal fisheries using hand jigs, pots, trammel nets and traps (Pita et al. 2015, Bañón et al. 2018). Fishing strategies and gear usage usually vary among regions, and industrial and artisanal fleets tend to fish different components of the population (Bañón et al. 2018, Sauer et al. 2020). The contribution to the overall catch from offshore trawl fisheries and artisanal fleets varies depending on the region, though catches from artisanal fleets are less well documented or unreported. Landings from coastal artisanal fisheries have high local economic and social importance in Southern Europe, but overall common octopus landings have declined since the mid-1980s (Pierce et al. 2010). In order to improve fisheries management and conservation strategies of $O$. vulgaris populations, diverse mark-and-recapture techniques have been conducted, usually working in close collaborations with fishermen, to improve the existing knowledge on individual movements and population dynamics (e.g. Fuentes and Iglesias 2010, Mereu et al. 2015, Arechavala-Lopez et al. 2018). However, many features cannot be investigated through fishing surveys, and therefore, direct observations in the field are required (Guerra et al. 2015). For example, direct underwater observations by visual censuses have been successfully applied to directly assess individual activity and specific ecological and behavioural traits of $O$. vulgaris populations in shallow coastal waters (e.g. Katsanevakis and Verriopoulos 2004a,b, Guerra et al. 2015). However, more detailed behavioural studies are difficult to perform in natural conditions, so experimental studies in captivity are sometimes a good tool for determining where to make the first steps and fill the gaps in existing knowledge.

Although $O$. vulgaris is one of the most widely and extensively studied species in terms of behaviour, personality and learning capabilities in captivity, there is a lack of studies concerning interactions between octopuses and fishing gears at individual level, which might be useful for implementing fisheries management strategies. In response to passive fishing gears such as trapping, behavioural differences at individual level might reflect a range of different person- alities and vulnerability levels within a population, which consequently might lead to a fishing-induced selection (Uusi-Heikkilä et al. 2008, Diaz-Pauli et al. 2015). Vulnerability (the odds of a single individual being captured by a specific fishing gear) defines the individual phenotype on which this fisheries selection acts (Uusi-Heikkilä et al. 2008) and drives dynamic population-level catchabilities (i.e. catches and harvesting efficiency), a key factor for stock assessment and fisheries management (Arreguín-Sánchez 1996). Vulnerability is, however, a complex and mildly inherited trait composed of a range of correlated physiological, behavioural, morphological and life-history traits that are influenced by phenotypic plasticity (e.g. learning) and ecological conditions (e.g. temperature) (Kortet et al. 2014, Dochtermann et al. 2015) relatively little effort has been put into trying to understand the selective effects of recreational angling. We conducted a long-term selection experiment to assess the heritability of vulnerability to angling in largemouth bass Micropterus salmoides. Three successive generations of artificially selected largemouth bass were produced from a single experimental study population. Within each generation, individual adult largemouth bass were identified as having either high or low vulnerability to angling through a series of controlled catch-and-release angling trials. Individuals of each vulnerability group (high and low. Quantifying vulnerability of target species to specific fishing gear (e.g. octopus traps) is challenging because it requires a comprehensive understanding of animal behaviour, physiology, morphology and cognition, as well as an appreciation of the controlling influence of external variables such as the social context and the abiotic and fishery environment (Lennox et al. 2017) handlining, angling, longlining, trolling, drumlining. Nevertheless, the individual vulnerability level within a group can be experimentally estimated following the classical foraging arena theory (Cox and Walters 2002) to better-understand the proportion of vulnerable and invulnerable animals in a population and obtain important information for the management of exploited species (Conrad et al. 2011, Mittelbach et al. 2014).

The first observations of cephalopods living in captive conditions gave an idea of the complexity of their behaviour and learning abilities (Piéron 1911), leading to a wide variety of studies on body postures, locomotion, personality and learning capabilities of some octopus species (Hanlon and Messenger 2018, and references therein). However, there are no studies addressing vulnerability or describing behavioural patterns of octopuses in the presence of different fishing gears. Therefore, the present study aims to describe for the first time the behavioural and body patterns of adult $O$. vulgaris facing baited traps in experimental conditions, assessing the individual differences and similarities. The results will provide important information about their ethology and vulnerability at both individual and species level, an aspect to be taken into account in the development of future strategies for management and conservation of this exploited species. 


\section{MATERIALS AND METHODS}

\section{Animal subjects and ethics}

Adult specimens of $O$. vulgaris $(\mathrm{n}=8$, six females and two males; mean body mass $\pm \mathrm{SE}=1.41 \pm 0.3$ ) were caught by octopus traps in October-November 2017 at coastal waters of Port d'Andratx (Mallorca, Spain) and immediately transported to the experimental laboratory in buckets with seawater (less than 10 mins) (Arechavala-Lopez et al. 2018). Once in the laboratory, captured octopuses were weighed, sexed and placed individually in circular tanks (volume, $1000 \mathrm{~L}$, diameter $1.5 \mathrm{~m}$ ) with a previously filtered (mechanic and UV) open seawater circulating system. Each tank contained pebbles covering the bottom and a terracotta pot, which they immediately chose as their den. The water depth in the tank was $60 \mathrm{~cm}$ and the temperature range was $14^{\circ} \mathrm{C}$ to $16^{\circ} \mathrm{C}$ during the whole study period. The light intensity was kept as near to the natural conditions as possible by switching on and off a series of lamps according to the seasonal illumination rhythm at this latitude (Fiorito et al. 1990). A net was placed on top, covering the tank to prevent escape attempts, though under these conditions the animals did not try to escape from the tank. After testing, the health and general condition of the octopuses were checked and all of them were released at the same place where they were captured in the bay of Port d'Andratx. All the procedures with octopuses were approved by the Ethical Committee of Animal Experimentation (CEEA$\mathrm{OH}$ ref. 71/03/17) and carried out strictly by trained and competent personal, following the guidelines for care and welfare of cephalopods (Fiorito et al. 2015) based on the European Directive (2010/63/UE) and Spanish Royal Decree (RD53/2013) to ensure good practices for animal care, health and welfare.

\section{Experimental procedure and analyses}

After three days of acclimation, the octopuses were tested once daily (morning) for three test sessions on separate days in the same tank where they had acclimated. Each individual was top-recorded using Sony HDR-AS50 Action Cams and the recorded test sessions were subsequently examined on a high-resolution monitor for behavioural analysis. Each test consisted in immersing a commercial semi-cylindrical octopus trap $(40 \mathrm{~cm}$ long $\times 30 \mathrm{~cm}$ high $\times 30 \mathrm{~cm}$ wide, $12 \mathrm{~cm}$ opening funnel diameter) baited with mackerels (Trachurus trachurus) at the farthest distance from the octopus den inside the tank during one hour. To determine vulnerability of $O$. vulgaris, latency to first capture (i.e. entering the trap, capturing and placing on the bait) was recorded, as well as the frequency (number of events) and duration (lasting time) of each behaviour or body pattern observed in each test.

Repeatability of the experiment and variations of latency to first-capture (i.e. time spent to enter the trap and capture the bait) among individuals were assessed. The latency to first-capture (Capture ${ }_{i, t}, 24$ observations) is assumed to be normal distributed with mean and standard deviation given by:

Capture $_{i, t} \sim$ Normal (Intercept + Test $_{t}+$ Octopus $_{i}$, sd) $\quad$ (Eq. 1)

where Test $(\mathrm{n}=3)$ and Octopus $(\mathrm{n}=8)$ result from combining a fixed part and a random part. In the case of Test, the fixed part was the test order (time), whereas the random part (i.e. normally distributed values with zero mean and a standard deviation to be estimated) defines the test-specific scores, with the aim of accounting for repeated measures or any putative learning effect. In the case of Octopus, the fixed part was the octopus weight, whereas the random part (i.e., normally distributed values with zero mean and a standard deviation to be estimated) defines the octopus-specific scores. All the putative explanatory variables (test order and octopus weight) were mean-centred to avoid over-parametrization. The parameters of the models (Eq. 1) were estimated using a Bayesian approach. A Gamma distribution prior $($ scale $=0.01$, rate $=0.01$ ) was used for the tolerance (1/variance) of all the random effects. A normal distribution prior (mean $=0$ and $\mathrm{sd}=1^{-10}$ ) was used for Intercept and for the slopes of test and octopus weight. Samples from the joint posterior distribution were obtained using JAGS (http://mcmc-jags. sourceforge.net/ accessed 10 Oct 2019) (Plummer 2015) and the R2jags package (Su and Yajima 2015) from the $\mathrm{R}$ language and environment for statistical computing version 4.0.2, released 2020-06-22 (R Core Team 2020). The first 30000 iterations were discarded and only one out ten of the remaining iterations were kept in order to prevent autocorrelation. Posteriors were inferred from 30000 valid iterations after burning and thinning. MCMC convergence was assessed by visual inspection and using Rhat (at convergence, Rhat $=1$ ), the potential scale reduction factor. Note that those individuals that never captured the bait were assigned a latency of 2 hours (i.e. twice the total observed period). The criteria chosen to say that an effect is relevant was when $95 \%$ of the confidence interval did not include zero (Kruschke 2014). Note that observations are right-censored for latency time (i.e. the test lasted 3600 seconds, but octopuses that did not capture the prey were assigned a latency of 7200 seconds). Uncertainty for latency time larger than 7200 seconds was managed using the interval distribution in JAGS. An R-script with the (non-informative) priors for each of the estimated parameters and other technical details of the model, and the input data are provided as supplementary material to ensure reproducibility of the results. The criterion chosen to say that an effect was relevant was when 95\% of the Bayesian confidence interval (BCI) did not include zero (Kruschke 2014).

A total of 17 behaviours and body patterns were considered (11 body postures and movements and 6 skin patterns; see Table 1 for descriptions) on the basis of previous studies and ethograms of the same and similar octopus species (e.g. Borrelli et al. 2006, Ma- 
Table 1. - Ethogram of body patterns (i.e. body posture, movements and skin displays) exhibited by $O$. vulgaris during experimental tests facing a baited trap (= object).

\begin{tabular}{|c|c|c|}
\hline & Code & Description \\
\hline \multicolumn{3}{|l|}{ Body posture and movements } \\
\hline In den/resting & I & Subject stays within den or remains at the den entrance/side \\
\hline Arm exploration & A & Subject moves one or more arms laterally but does not touch any stimuli \\
\hline Body exploration & B & Subject moves slowly towards the object (trap) with the whole body, exploring but not touching. \\
\hline Crawl & $\mathrm{C}$ & Subject moves along the bottom using its arms as its means of locomotion \\
\hline Grabbing the trap & G & Subject approaches the new object (trap), touching and grabbing it with one or two arms only \\
\hline Pulling the trap & $\mathrm{E}$ & Subject pulls the grabbed object (trap) with one or two arms only \\
\hline Approaching the trap & $\mathrm{F}$ & Subject rapidly approaches the object (trap) with more than two arms, moving head and mantle \\
\hline Capturing prey/bait & Y & Subject displays web-over capture attempt and feeds on the bait. \\
\hline Retreat & $\mathrm{H}$ & Subject moves towards the den at increasing distance from the stimulus (prey, object, human presence) \\
\hline Defence/Alert & $\mathrm{D}$ & Subject remains still, flattened on the bottom with no visible reaction or contact with den \\
\hline Jet swim & $\mathrm{J}$ & Subject moves by jet propulsion, with no contact with the bottom or sides of the tank \\
\hline \multicolumn{3}{|l|}{ Skin displays } \\
\hline Regular texture/pattern & $\mathrm{R}$ & Subject's overall skin shows papillae and grain texture with coloured mottles of low contrast all over the body \\
\hline Smooth texture & $\mathrm{S}$ & Subject's overall skin papillae relaxed, with no bumps of 3D skin texture \\
\hline Hood/striped pattern & $\mathrm{N}$ & Subject shows a black hood between eyes that could be extended through mantle laterals and arms. \\
\hline Broad mottle & M & Subject's overall skin shows small splotches of dark and light of high contrast all over the body \\
\hline Passing cloud & $\mathrm{O}$ & Uniform dark flush that passes outwards from the head over the dorsal region of arms and web \\
\hline Dark pattern & $\mathrm{Z}$ & Sudden uniform darker colouration in subject's overall skin \\
\hline
\end{tabular}

ther and Alupay 2016 and references therein). Furthermore, sequential behaviours and body patterns were assessed by transition matrices based on frequencies and proportional occurrences of each observed sequence. These matrices were used to construct kinematic diagrams of behavioural and body patterns transitions, which visually depict the frequency and duration of each behaviour or body pattern, as well as the occurrence of each transition at both individual and group level. A kinematic diagram gives an excellent overview of behavioural sequences and how frequently certain behaviours occur (Brockmann 1994). Transitions that occurred more than $1 \%$ of the time throughout an interaction were included in the kinematic diagrams. A principal component analysis (PCA) was applied as an ordination method to assess the contribution of observed behaviour and body patterns (variables) on the differences among individuals facing a baited trap. All the data were centred and scaled using the prcomp command from the stats R Package. Moreover, a Pearson's correlation analyses were applied to assess relationships among recorded behaviour and body patterns.

\section{RESULTS}

A total of five octopuses (1, 2, 3, 4 and 5) entered the trap and captured the bait (Y) across all three experimental tests, whereas only one octopus captured the bait in two tests (7) and two octopuses only once (6 and 8$)$. It must be noted that some octopuses (1, 3, 4, 5 and 8 ) were able to move out from the trap and come back again on top of the bait during the recording time, but only first capture (Y) was considered for further analyses. Overall, latency to first capture ranged from $2.1 \mathrm{~min}$ to $38.25 \mathrm{~min}$ (mean latency $12.5 \mathrm{mins}$ ), but the Bayessian model revealed no relevant differences among octopus individuals (I,e. 95\% BCI includes zero) (see Supplementary Materials: Figure S1 and Table S1) and the estimated median repeatability was less than $0.001(0-0.56186$ BCI 95\%). Altogether, the most frequent behaviours (e.g. body posture and movements) recorded until first capture (Y) occurred were approaching the trap $\left(\mathrm{F} ; 2.6 \pm 0.9\right.$ times test $\left.^{-1}\right)$, grabbing the trap $\left(\mathrm{G} ; 1.9 \pm 0.8\right.$ times test $\left.^{-1}\right)$ and resting inside the den (I; $1.2 \pm 0.5$ times test $\left.^{-1}\right)$ (Fig. 1). In terms of duration, subjects spent most of the time approaching the bait $(\mathrm{F}$; $\left.118.1 \pm 19.3 \mathrm{sec} \mathrm{test}^{-1}\right)$ and resting in the den $(\mathrm{I} ; 35.4 \pm 9.8$ sec test ${ }^{-1}$ ) (Fig. 1). Regarding skin patterns until first capture $(\mathrm{Y})$, the regular pattern was the most frequent $\left(\mathrm{R} ; 3.2 \pm 0.9\right.$ times test $\left.^{-1}\right)$ and long-lasting (131.1 \pm 60.6 sec test $\left.\mathrm{t}^{-1}\right)$, followed by dark $\left(\mathrm{Z} ; 1.5 \pm 0.9\right.$ times test ${ }^{-1}$, $20.5 \pm 7.3 \mathrm{sec}$ test $\left.^{-1}\right)$, passing cloud $(\mathrm{O} ; 1.1 \pm 0.5$ times test $^{-1} ; 18.1 \pm 8.5 \mathrm{sec}$ test $\left.^{-1}\right)$ and broad mottle patterns (M; 0.8 \pm 0.3 times test $^{-1} ; 16.9 \pm 7.0 \mathrm{sec}$ test $^{-1}$ ) (Fig. 1). A kinematic diagram for all octopuses was built based on 477 sequences (Fig. 2). Among all behaviours and body patterns observed, the most exhibited transition chain according to occurrence, frequency and duration was resting in the den (I), followed by grabbing the trap (G) and/or approach (F), showing a regular skin pattern (R) and capturing bait (Y) (Fig. 2).

However, kinematic diagrams differed among individuals (Fig. 3). For example, the diagram of octopus 1 was based on 52 sequences from a total of 13 behaviours and body patterns, approaching the trap (F), regular $(\mathrm{R})$ and broad mottle $(\mathrm{M})$ skin patterns being the most frequently observed. The diagram of octopus 2 was based on 17 sequences from 7 behaviours and body patterns, where approaching the trap $(\mathrm{F})$, capturing the bait (Y), broad mottle skin (M) and alert position (D) were the most frequent ones. The diagram of octopus 3 was based on 77 sequences, and a total of 12 behaviours and body patterns were observed, where arm exploration (A), pulling (E), grabbing (G) 

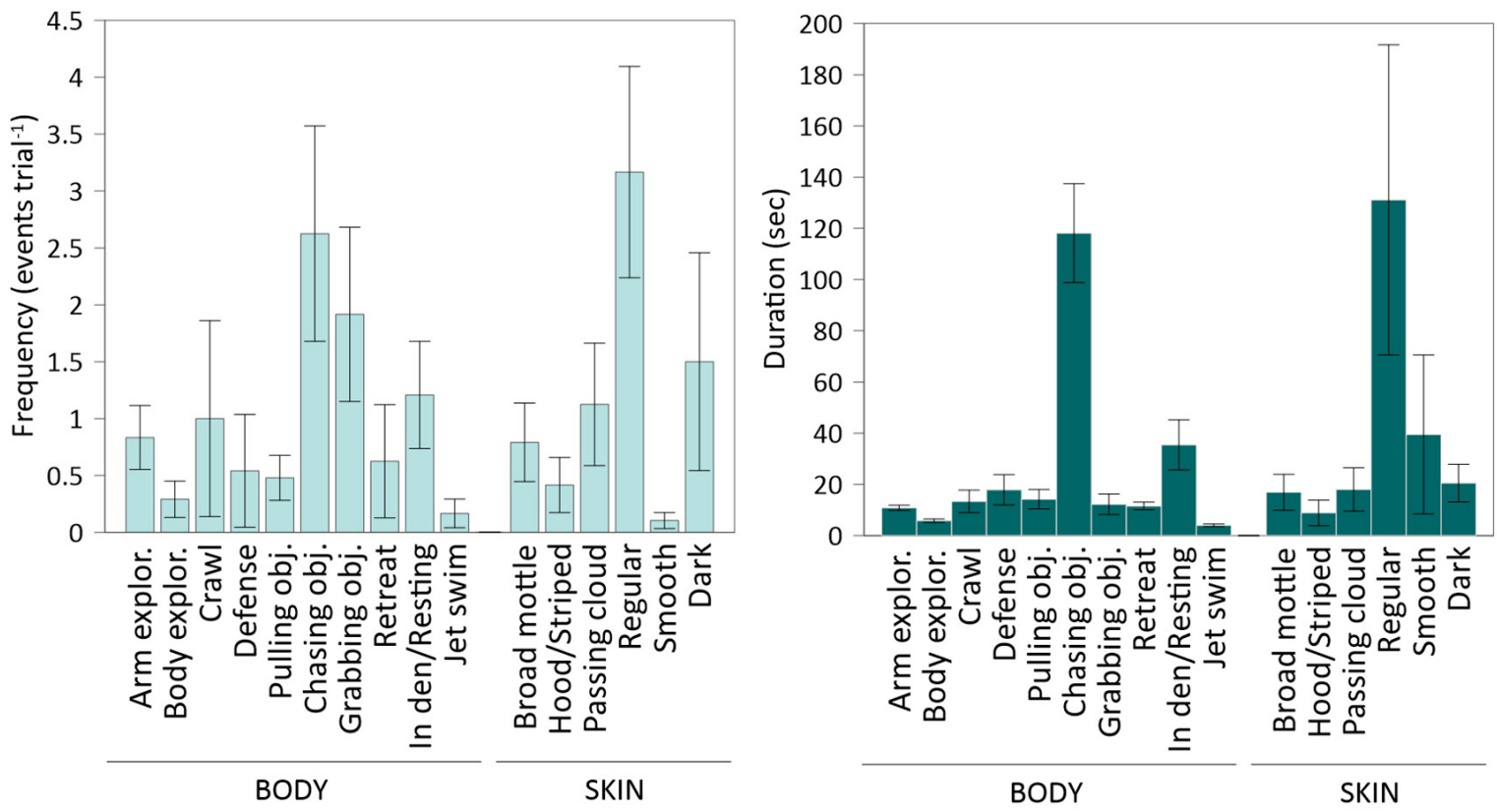

Fig. 1. - Mean frequency (events per trial) and duration (in sec.) of behaviour and body patterns observed (body postures, movements and skin displays) in $O$. vulgaris during the experimental trials when faced with a baited trap until first-capture events.

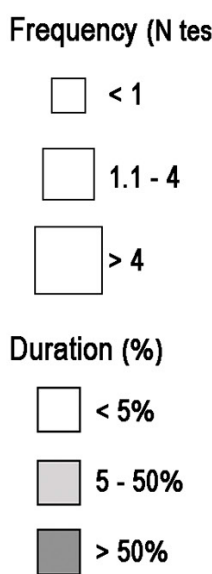

Ocurrence

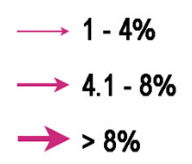

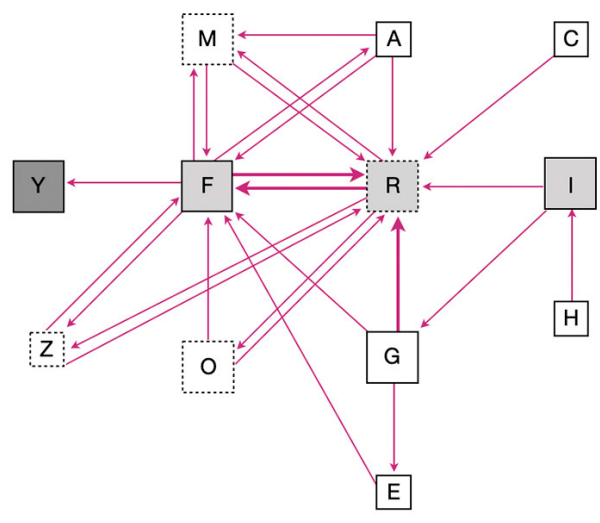

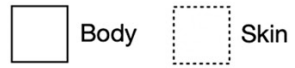

Body
A: Arm exploration
B: Body exploration
C: Crawl
D: Defense/Alert
E: Pulling object
F: Object approach
G: Grabbing object
$\mathrm{H}$ : Retreat
I: Resting / In den
J: Jet swim
Y: Capture bait/prey

Skin
M: Broad mottle
$\mathrm{N}$ : Hood/Striped
0 : Passing cloud
R: Regular skin
$\mathrm{S}$ : Smooth texture
Z: Dark pattern

Fig. 2. - Kinematic diagrams of general behaviours and body patterns of all $O$. vulgaris observed during the experiment. The size and colours of bounding boxes around the behaviours is proportional to the relative frequency and duration of a particular behavioural pattern, respectively. Paired behaviour sequences are depicted as arrows. The magnitude of the occurrence of each paired sequence is shown by the arrow size. Transitions that occurred less than $1 \%(<0.01)$ of the time during an interaction were excluded. The continuous line squares show the body posture and movements, whereas the discontinuous line squares show the skin patterns.

and approaching the trap $(\mathrm{F})$, capturing the bait $(\mathrm{Y})$ and diverse skin patterns such as regular $(\mathrm{R})$, broad mottle (M) and dark (Z) patterns were shown with higher frequency during the experimental tests. The diagram of octopus 4 was based on 125 sequences from 10 behaviours and body patterns, where approaching the trap (F) was the most frequent behaviour and regular skin (R) was the longest skin pattern observed. The diagram of octopus 5 was based on 26 sequences, and a total of nine behaviours and body patterns were observed, grabbing $(\mathrm{G})$, pulling $(\mathrm{E})$ and approaching $(\mathrm{F})$ the trap, together with capturing the bait (Y), being the most frequent behaviours, and regular $(\mathrm{R})$ and smooth $(\mathrm{S})$ skin were the most frequent skin patterns observed. The diagram of octopus 6 was based on 117 sequences from 11 behaviours and body patterns, where grabbing the trap $(\mathrm{G})$, approaching the trap $(\mathrm{F})$, crawling $(\mathrm{C})$, regular skin $(\mathrm{R})$ and dark skin pattern $(\mathrm{Z})$ were the most 

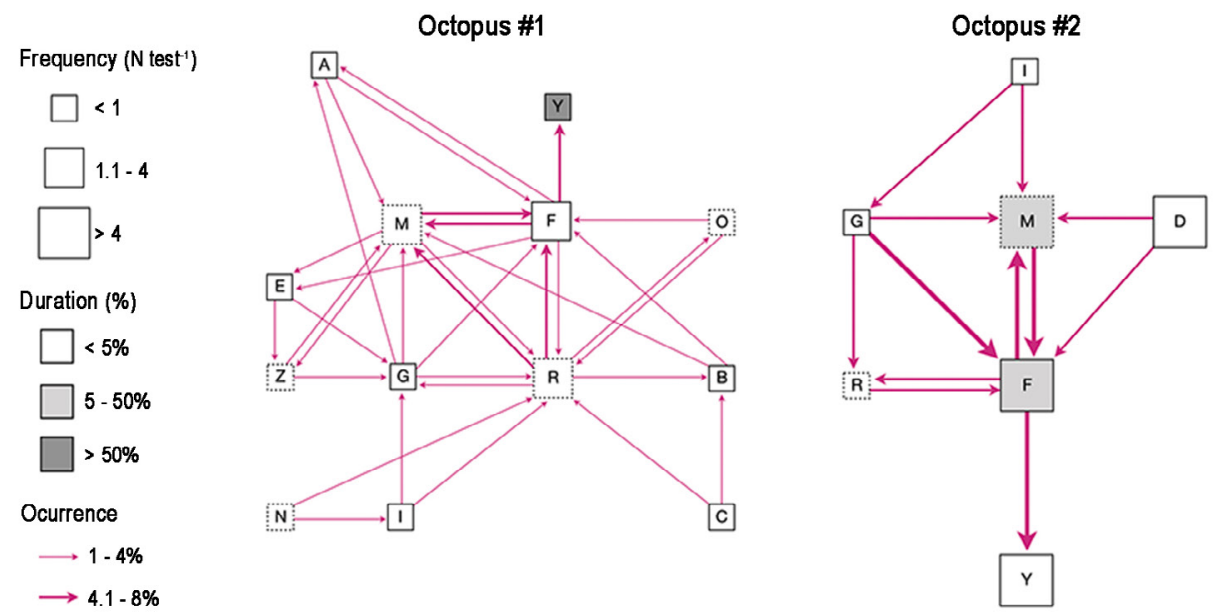

$\longrightarrow$
$\longrightarrow$

$\rightarrow>8 \%$

Body

Skin

A: Arm exploration

B: Body exploration

C. Craw

D: Defense/Alert

E: Pulling object

$\mathrm{F}:$ Object approach

G: Grabbing object

H: Retreat

I: Resting / In den

J: Jet swim

$\mathrm{Y}$ : Capture bait/prey

M: Broad mottle

N: Hood/Striped

O: Passing cloud

R: Regular skin

S: Smooth texture

Z: Dark pattern

Octopus \#3
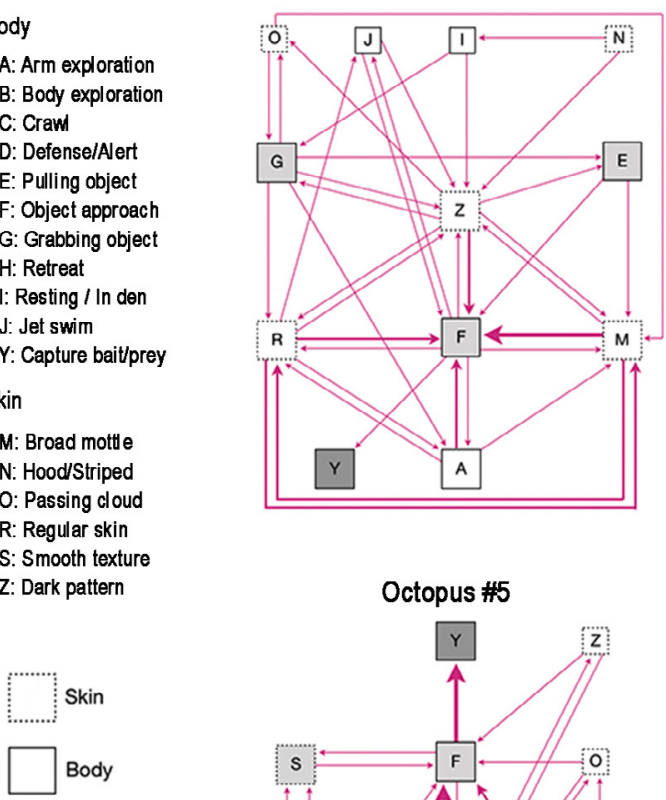

Octopus \#5
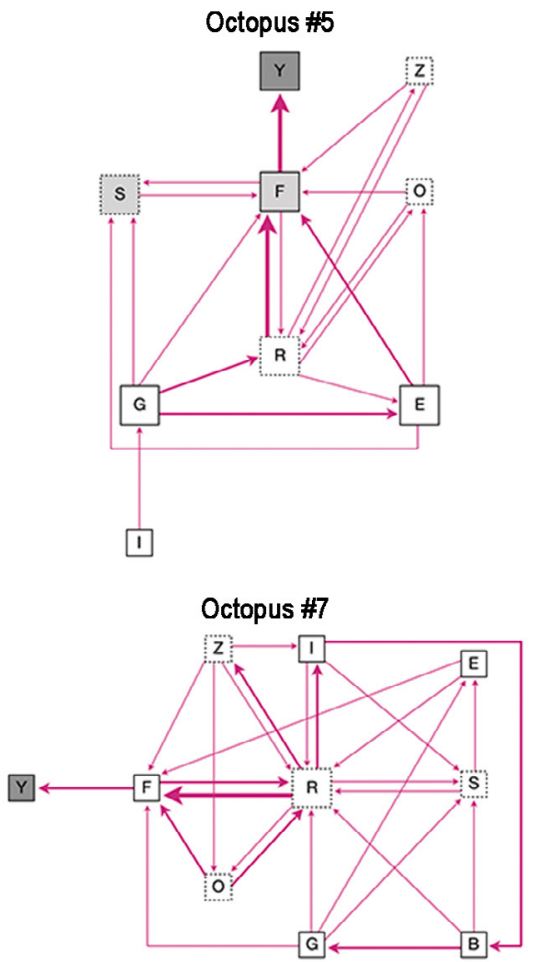

Octopus \#4

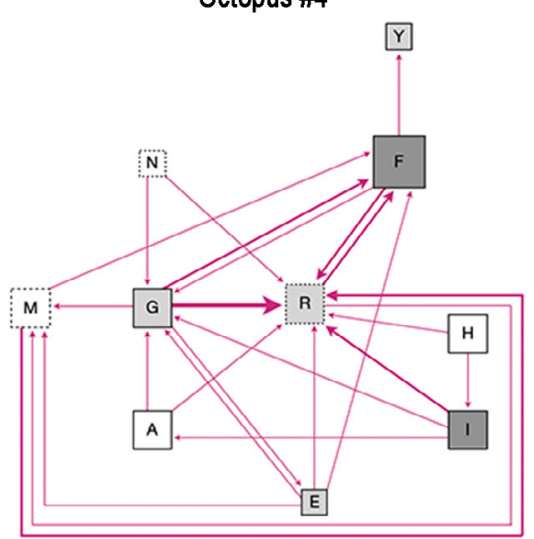

Octopus \#6

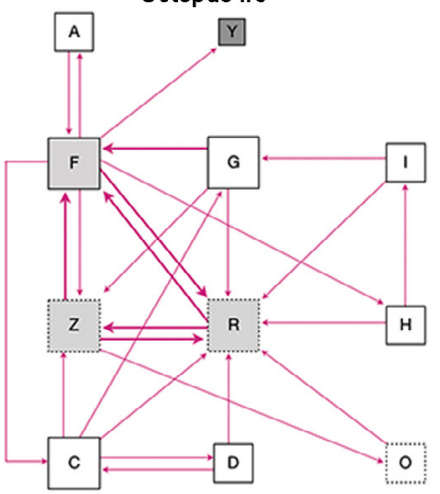

Octopus \#8

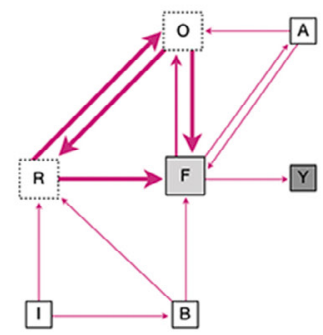

Fig. 3. - Kinematic diagrams of individual behaviours and body patterns of $O$. vulgaris observed during the experiment. The size and colours of bounding boxes around the behaviours is proportional to the relative frequency and duration of a particular behavioural pattern, respectively. Paired behaviour sequences are depicted as arrows. The magnitude of the occurrence of each paired sequence is shown by the arrow size. Transitions that occurred less than $1 \%(<0.01)$ of the time during an interaction were excluded. The continuous line squares show the body posture and movements, whereas the discontinuous line squares show the skin patterns. 


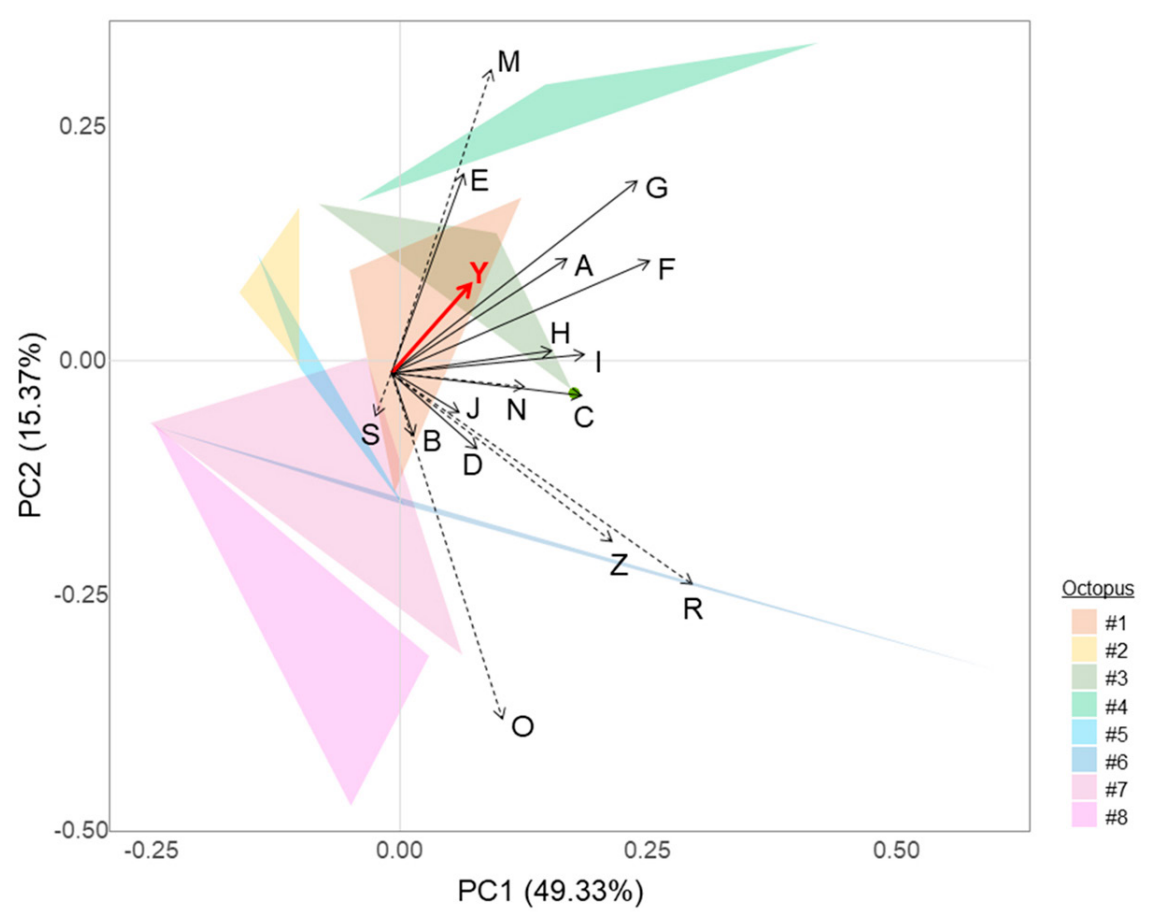

Fig. 4. - Scatterplot of two main principal components for $O$. vulgaris individuals regarding observed behaviour (continuous black vectors) and body patterns (dotted vectors) during the experimental tests. The red vector shows capturing the bait $(\mathrm{Y})$. The coloured triangles were built according to the results of the three tests performed on each individual. A, arm exploration; B, body exploration; C, crawl; D, defence position; E, pulling the trap; F, approaching the trap; G, grabbing the trap; H, retreat; I, resting in the den; J, jet swim; Y, capture bait/prey; M, broad mottle skin; N, hood/striped skin pattern; O, passing cloud skin pattern; R, regular skin pattern; S, smooth texture; Z, dark skin pattern.

frequent ones. The diagram of octopus 7 was based on 38 sequences, and a total of 10 behaviours and body patterns were observed, showing the regular skin pattern $(\mathrm{R})$ with higher frequency and capturing and feeding on top of the bait $(\mathrm{Y})$ during the longest periods. The diagram of octopus 8 was based on 25 sequences from seven behaviours and body patterns, approaching the bait $(\mathrm{F})$ being the most frequent behaviour and capturing the prey $(\mathrm{Y})$ the most durable one, and regular $(\mathrm{R})$ and passing cloud $(\mathrm{O})$ were the most frequent skin patterns observed.

Individual differences based on the behavioural and body patterns recorded can be visually observed in the PCA plot (Fig. 4). A combination of two principal components explained $64.69 \%$ of the total variation of behavioural and body patterns among octopus individuals and tests (Fig. 4). Principal component 1 (PC1) explained $49.33 \%$ of total variation and mainly comprised the variations in regular skin pattern (R: 19.6\%), approaching (F: 14.52\%) and grabbing the trap $(\mathrm{G}$ : $13.09 \%)$, dark skin pattern (Z: $10.6 \%)$, and resting in the den (I: 8.2\%) (Fig. 4). Principal component 2 (PC2) explained $15.37 \%$ of the total variation, and the main contributors were skin patterns such as passing cloud (O: 29.25\%), broad mottle (M: 22.45\%) and regular skin (R: 10.82\%), in addition to pulling (E: 9.72\%) and grabbing (G: 9.01\%) behaviours (Fig. 4). Regarding relationships between capturing the prey $(\mathrm{Y})$ and the rest of the behaviours and body patterns, multivariate correlation analyses only showed a significant correlation with trap approach $\left(F ; R^{2}=0.42\right.$, p-value $\left.=0.04\right)$, but there were no significant correlations ( $\mathrm{p}$-value $>0.05$ ) with the other recorded variables (see Supplementary Material: Table S2).

\section{DISCUSSION}

This study shows for the first time that behavioural and body pattern reactions of $O$. vulgaris when facing a baited trap differ among individuals. In general, when octopuses were exposed to the baited trap, they visually recognized new objects or potential preys and rapidly moved out the den, exploring and pulling the baited trap with the arms (A, E), approaching, grabbing and entering the trap $(\mathrm{F}, \mathrm{G})$, capturing the bait with the arms and feeding on top over long periods of time (Y) (see Sauer et al. 2020). Simultaneously, O. vulgaris displayed diverse skin changes and patterns, the regular pattern (R) being the most frequent and long-lasting, followed by broad mottle (M), passing cloud (O) and dark skin (Z) patterns. The skin of cephalopods plays an important role in communication, which is largely visual and obviously relies upon the complexity and efficiency of their eyes, and serves either for concealment or expressions (Borrelli et al. 2006). Although the skin presents the animals' appearance in a specific moment, changes in the display system are based on motor control and so are examined in the assessment of cephalopod movement (Mather and Alupay 2016). Overall, the observed general sequence of behaviours and body patterns is qualitatively similar to that found in previous studies on $O$. vulgaris preying on crustaceans 
(Packard 1963, Maldonado 1964, Amodio et al. 2014) and bivalve molluscs (Fiorito and Gherardi 1999) or facing puzzling-rewarded experiments (Fiorito et al. 1990, Mather 1991b). This behavioural pattern is extensively used in the wild by $O$. vulgaris, commonly defined as visual and chemotactile exploration, where they first visualize likely food spots and then explore crevices, rock surfaces, clumps of algae or the sea-bed with their arms, arm webs, tips and suckers in search of possible preys (Mather 1991a). In this experiment, common octopus might have learnt how to approach the trap given that they were captured from the wild by similar fishing traps, and also as a result of repeated exposures throughout the experimental tests. However, problem-solving experiments carried out on $O$. vulgaris demonstrated that when individuals are exposed to a puzzling situation or tasks, they do not appear to be able to reduce the time spent in exploratory behaviour (Fiorito et al. 1990). Although there were no relevant differences among individuals regarding the time of first capture, not all individuals entered the trap and captured the bait in all tests. Indeed, variations among individuals in behavioural and body pattern responses facing the baited trap were found in this study. When $O$. vulgaris was exposed to a feeding context in which the challenge of reaching the bait inside the trap was implemented, they performed a wide range of behaviours, movements and body patterns, which also varied in terms of frequency and duration and might evidence different individual temperaments of each $O$. vulgaris individual, though this is difficult to determine. Due to the short time and low repeatability of our experiments, it cannot be stated that behavioural traits are consistent over time.

Previous behavioural studies demonstrated that octopuses have both inter- and intraspecific differences (Mather and Anderson 1993, Sinn et al. 2001, Pronk et al. 2010). Mather and Anderson (1993) tested Octopus rubescens in three situations (alerting, threat and feeding) and suggested that octopus personalities vary in three dimensions, which they defined as activity (active-inactive), reactivity (anxious-calm) and avoidance (avoiding-bold). Sinn et al. (2001) followed the development of individual differences through the first nine weeks of Octopus bimaculatus lives, suggesting four dimensions of temperament: arousal/readiness, active engagement, aggression and avoidance/disinterest. Pronk et al. (2010) exposed Octopus tetricus individuals to three different contexts (foraging, novel object and threatening) using video playback, and concluded that the octopus does not have personality but rather an "episodic" personality. They observed that inter-individual differences in behaviour were consistent across multiple contexts, but none of the personality traits were repeatable over time (intra-individual variations). Repeatability in our experiment was low (0.1), and individual differences can be observed through the kinematic diagrams and PCA analyses. For example, some octopuses (2 and 5) showed a direct and active predation behaviour, moving rapidly towards the trap (F), commonly exhibiting regular $(\mathrm{R})$ or broad mottle pattern skin $(\mathrm{M})$ and en- tering the trap to capture the bait (Y). Together with regular grain texture and colour pattern $(\mathrm{R})$, the broad mottle pattern is suggested to be used for background matching in absence of threat or as a response to potential disturbance, in combination with a wide range of body movements and postures (Packard and Sanders 1971; Mather and Alupay 2016). Other octopuses (1, 3 and 4) performed a wider range of behaviour and body pattern combinations, and although they also captured the prey in a short period of time, they seemed to behave more cautiously, exploring from the shelter before leaving (A) or pulling the trap trying to bring it closer (E). Moreover, they also exhibited body patterns of distrust and aggressiveness during approaching movements, such as a flush to a sudden uniform dark colouration $(\mathrm{Z})$, considered as an act of aggression, or a passing cloud skin pattern $(\mathrm{O})$, which is often directed towards objects and is usually a startle directed to potential prey (Packard and Sanders 1971; Mather and Alupay 2016). Additionally, other octopuses $(6,7$ and 8$)$ neither entered the trap nor captured the bait in some trials during the observed experimental period, which might suggest a more timid or distrustful temperament. Nevertheless, it could be possible that motivational states varied within and among days as a function of varying levels of hunger, accumulated experiences or variations in the laboratory/experimental conditions (Mather and Anderson 1993, Pronk et al. 2010).

Octopuses have considerable behavioural flexibility and a strong tendency to adapt themselves to diverse conditions and to learn (Mather 1991b, Hanlon and Messenger 2018), which allows them to change their behaviour adaptively over time, optimizing it in a variety of typical environmental conditions (Fiorito and Gherardi 1999, Van Buskirk 2002). These aspects shape their natural history as far as their phylogeny. For example, feeding adaptations are considered to have made an important contribution to the evolutionary success of this taxon (Packard 1972, Mather and O'Dor 1991). However, life-history traits are among the prime targets of fisheries-induced selection, which affects any trait that determines how individuals are exposed to fishing (Heino et al. 2015). The interest in fishing-induced life-history evolution in fish stocks has been growing in the last decade, in part because of the increasing number of fish studies suggesting evolutionary changes in life-history traits, and the potential ecological and economic consequences these changes may have (Enberg et al. 2012). There is now increasingly firm evidence that passively operated gears such as trapping, pots and gill nets, which are common in many commercial fisheries, preferentially catch bold, aggressive, explorative or active fish individuals, leaving behind stocks whose individuals are less aggressive and more timid (Diaz-Pauli et al. 2015). The results draw attention to the importance of the behavioural dimension of fishing: selective fishing based on behavioural traits will change the trait composition of the population and might eventually affect resilience and fishery productivity (Arlinghaus et al. 2017). However, the extent to which life-history traits of cephalopods 
in general, and octopuses in particular, are likely to experience fisheries-induced selection remains to be assessed.

The common octopus is a worldwide important marine resource, which has gained market value in recent decades, with very important markets in Southern Europe (e.g. Spain, Portugal, Italy and Greece) and Asia (e.g. Japan) (FAO 2020). Octopus is caught by both industrial trawlers and artisanal vessels, the latter being responsible for the majority of the overall landings. Traps and pots are traditionally used along the coasts of the Iberian Peninsula (e.g. Bañón et al. 2018; Sauer et al. 2020). Therefore, understanding the individual vulnerability of common octopus and their relationship with the dynamics of small-scale trap fisheries is essential to manage possible effects on the life history of octopus populations as well as to improve the sustainability of the octopus fishery. First, the traps could capture first those individuals who are more active and exploratory, given that the probability of encountering the trap is greater in individuals with higher activity range (Arechavala-Lopez et al. 2018) and those with higher catchability due to a bolder behavioural trait of entering the trap to feed the bait. Second, traps can also act as a refuge for some octopuses in areas where dens are scarce or highly competitive, and therefore capture a part of the population that has a different temperament but is still vulnerable. Moreover, octopus traps can sometimes be lost and become ghost-traps, fishing octopuses and other living organisms for long periods (up to two weeks in particular for common octopus), albeit with decreasing efficiency over time, but with no control of fishermen over the gear (Erzini et al. 2008). Therefore, the particularities of fishing traps raise new questions about the possible fisheries-induced effects on common octopus populations.

These are, to the best of our knowledge, the first published data on $O$. vulgaris exposed to passive fishing gears. Here we demonstrated that $O$. vulgaris, a highly exploited and appreciated species worldwide, may show diverse temperaments that lead to a range of individual vulnerability levels when they face usual and traditional fishing traps. This may have population consequences due to fisheries-induced selection. Therefore, it is urgent to assess how behavioural traits might play an important role in the life-history traits of the species and in the conservation and management of octopus populations, and we hope that this study can help to move towards this end.

\section{ACKNOWLEDGEMENTS}

This work is a contribution of the Joint Associated Unit IMEDEA-LIMIA. G.F-B. was supported by a Spanish PhD fellowship (FPI-INIA) from the National Institute for Agricultural and Food Research and Technology (INIA). P.A.L. was supported by a post-doctoral grant (Juan de la Cierva-Incorporación; IJCI2015-25595) from the Spanish Ministry of Economy, Industry and Competitiveness. We would like to thank LIMIA staff members for helping with daily experimental maintenance and animal care.

\section{REFERENCES}

Amodio P., Andrews P., Salemme M., et al. 2014. The use of artificial crabs for testing predatory behavior and health in the octopus. ALTEX - Alternatives Anim. Experiment. 31: 494-499. https://doi.org/10.14573/altex.1401282s

Amor M.D., Norman M.D., Roura A., et al. 2017. Morphological assessment of the Octopus vulgaris species complex evaluated in light of molecular-based phylogenetic inferences. Zool. Script. 46: 275-288. https://doi.org/10.1111/zsc.12207

Arechavala-Lopez P., Minguito-Frutos M., Follana-Berná G., et al. 2018. Common octopus settled in human-altered Mediterranean coastal waters: from individual home range to population dynamics. ICES J. Mar. Sci. 76: 585-597. https://doi.org/10.1093/icesjms/fsy014

Arlinghaus R., Laskowski K.L., Alós J., et al. 2017. Passive gearinduced timidity syndrome in wild fish populations and its potential ecological and managerial implications. Fish Fish. 18: 360-373. https://doi.org/10.1111/faf.12176

Arreguín-Sánchez F. 1996. Catchability: a key parameter for fish stock assessment. Rev Fish Biol Fish. 6: 221-242. https://doi.org/10.1007/BF00182344

Bañón R., Otero J., Campelos-Álvarez J.M., et al. 2018. The traditional small-scale octopus trap fishery off the Galician coast (Northeastern Atlantic): Historical notes and current fishery dynamics. Fish. Res. 206: 115-128. https://doi.org/10.1016/j.fishres.2018.05.005

Borrelli L., Gherardi F., Fiorito G. 2006. A catalogue of body patterning in cephalopoda. Firenze University Press. Firenze, Italy. https://doi.org/10.36253/88-8453-376-7

Brockmann H.J. 1994. Measuring behaviour: Ethograms, kinematic diagrams, and time budgets. Technical document, Department of Biology, University of Florida, USA.

Conrad J.L., Weinersmith K.L., Brodin T., et al. 2011. Behavioural syndromes in fishes: a review with implications for ecology and fisheries management. J. Fish Biol. 78: 395-435. https://doi.org/10.1111/j.1095-8649.2010.02874.x

Cox S.P., Walters C. 2002. Modeling Exploitation in Recreational Fisheries and Implications for Effort Management on British Columbia Rainbow Trout Lakes. North Am J Fis. Manag. 22: 21-34. https://doi.org/10.1577/1548-8675(2002)022<0021:MEIR$\mathrm{FA}>2.0 . \mathrm{CO} ; 2$

Diaz-Pauli B., Wiech M., Heino M., et al. 2015. Opposite selection on behavioral types by active and passive fishing gears in a simulated guppy Poecilia reticulata fishery. J.Fish Biol. 86: $1030-1045$. https://doi.org/10.1111/ifb.12620

De Luca D., Catanese G., Procaccini G., et al. 2016. Octopus vulgaris (Cuvier, 1797) in the Mediterranean Sea: Genetic diversity and population structure. PloS ONE, 11: e0149496. https://doi.oro/10.1371/journal pone.0149496

Dochtermann N.A., Schwab T., Sih A. 2015. The contribution of additive genetic variation to personality variation: heritability of personality. Proc. Biol. Sci. 282: 20142201. https://doi.org/10.1098/rspb.2014.2201

Enberg K., Jørgensen C., Dunlop E.S., et al. 2012. Fishing-induced evolution of growth: concepts, mechanisms and the empirical evidence. Mar. Ecol. 33: 1-25. https://doi.org/10.1111/j.1439-0485.2011.00460.x

Erzini K., Bentes L., Coelho R., et al. 2008. Catches in ghost-fishing octopus and fish traps in the northeastern Atlantic Ocean (Algarve, Portugal). Fish. Bull. 106: 321-327.

FAO. 2020. Fisheries and Aquaculture Information and Statistics Branch - 16/09/2020. FAO Ed.

Fiorito G., Gherardi F. 1999. Prey-handling behaviour of Octopus vulgaris (Mollusca, Cephalopoda) on bivalve preys. Behav. Proc. 46: 75-88. https://doi.org/10.1016/S0376-6357(99)00020-0

Fiorito G., von Planta C., Scotto P. 1990. Problem solving ability of Octopus vulgaris lamarck (Mollusca, Cephalopoda). Behav. Neur. Biol. 53: 217-230. https://doi.org/10.1016/0163-1047(90)90441-8

Fiorito G., Affuso A., Basil J., et al. 2015. Guidelines for the care and welfare of Cephalopods in research $\triangle A$ consensus based on an initiative by CephRes, FELASA and the Boyd Group. Laboratory Animals, 49: 1-90. https://doi.org/10.1177/0023677215580006 
Fuentes L., Iglesias J. 2010. Release experiments with Octopus vulgaris Cuvier, 1797 in Galicia, NW Spain. First results on recapture rate, distribution and growth. Vie et Milieu 60: $65-71$.

Guerra Á., Hernández-Urcera J., Garci M.E., et al. 2014. Dwellers in dens on sandy bottoms: Ecological and behavioural traits of Octopus vulgaris. Sci. Mar. 78: 405-414. https://doi.org/10.3989/scimar.04071.28F

Guerra Á., Hernández-Urcera J., Garci M.E., et al. 2015. Spawning habitat selection by Octopus vulgaris: new insights for a more effective management of this resource. Fish. Res. 167: 313-322. https://doi.org/10.1016/j.fishres.2015.03.011

Hanlon R.T., Messenger J.B. 2018. Cephalopod behaviour. Cambridge University Press. https://doi.org/10.1017/9780511843600

Heino M., Pauli B.D. Dieckmann U. 2015. Fisheries-induced evolution. Ann. Rev. Ecol. Evol. System. 46: 461-480. https://doi.org/10.1146/annurev-ecolsys-112414-054339

Jereb P., Allcock L.A., Lefkaditou E., et al. 2015. Cephalopod biology and fisheries in Europe: II. Species Accounts. ICES.

Katsanevakis S., Verriopoulos G. 2004a. Abundance of Octopus vulgaris on soft sediment. Sci. Mar. 68: 553-560. https://doi.org/10.3989/scimar.2004.68n4553

Katsanevakis S., Verriopoulos G. 2004b. Den ecology of $O c$ topus vulgaris Cuvier, 1797, on soft sediment: availability and types of shelter. Sci. Mar. 68: 147-157. https://doi.org/10.3989/scimar.2004.68n1147

Kortet R., Vainikka A., Janhunen M., et al. 2014. Behavioral variation shows heritability in juvenile brown trout Salmo trutta. Behav Ecol Sociobiol. 68: 927-934. https://doi.org/10.1007/s00265-014-1705-z

Kruschke J. 2014. Doing Bayesian data analysis: A tutorial with R, JAGS, and Stan. Academic Press. https://doi.org/10.1016/B978-0-12-405888-0.00008-8

Lennox R.J., Alós J., Arlinghaus R., et al. 2017. What makes fish vulnerable to capture by hooks? A conceptual framework and a review of key determinants. Fish Fish. 18: 9861010 . https://doi.org/10.1111/faf.12219

Maldonado H. 1964. The control of attack by Octopus. J. Comp. Physiol. A: Neuroethol. Sensor. Neur. Behav. Physiol. 47: 656-674 https://doi.org/10.1007/BF00303314

Mather J.A. 1991a. Foraging, feeding and prey remains in middens of juvenile Octopus vulgaris (Mollusca: Cephalopoda). J. Zool. 224: 27-39. https//doi.oro/10.1111/j 1469-7998 1991 tb04786.x

Mather J.A. 1991b. Navigation by spatial memory and use of visual landmarks in octopuses. J. Comp. Physiol. A: Neuroethol. Sensor. Neur. Behav. Physiol. 168: 491-497. https://doi.org/10.1007/BF00199609

Mather J.A., Alupay J.S. 2016. An ethogram for Benthic Octopods (Cephalopoda: Octopodidae). J. Comp. Psychol. 130: 109-127. https://doi.org/10.1037/com0000025

Mather J.A., Anderson R.C. 1993. Personalities of octopuses (Octopus rubescens). J. Comp. Psychol. 107(3): 336-340. https://doi.org/10.1037/0735-7036.107.3.336

Mather J.A., O'Dor R.K. 1991. Foraging strategies and predation risk shape the natural history of juvenile Octopus vulgaris. Bul. Mar. Sci. 49: 256-269.

Mereu M., Agus B., Addis P., et al. 2015. Movement estimation of Octopus vulgaris Cuvier, 1797 from mark recapture experiment. J. Exp. Mar. Biol. Ecol. 470: 64-69. https://doi.org/10.1016/j.jembe.2015.05.007

Mittelbach G.G., Ballew N.G., Kjelvik M.K. 2014. Fish behavioral types and their ecological consequences. Can. J. Fish. Aqua. Sci. 71: 927-944. https://doi.org/10.1139/cjfas-2013-0558

Packard A. 1963. The behaviour of Octopus vulgaris. Bull. Inst. Oceanogr. (Monaco) D 1: 35-49.
Packard A. 1972. Cephalopods and fish: the limits of convergence. Biol. Rev. 47: 241-307. https://doi.org/10.1111/j.1469-185X.1972.tb00975.x

Packard A., Sanders G.D. 1971. Body patterns of Octopus vulgaris and maturation of the response to disturbance. Anim. Behav. 19: 780-790. https://doi.org/10.1016/S0003-3472(71)80181-1

Pierce G.J., Allcock L., Bruno I., et al. 2010. Cephalopod biology and fisheries in Europe. ICES.

Piéron H. 1911. Contribution a la psychologie du poulpe. Bull. l'Inst. Gén. Psychol. 11: 111-119.

Pita C., Pereira J., Lourenço S., et al. 2015. The traditional small-scale octopus fishery in Portugal: framing its governability. In: Interactive Governance for Small-Scale Fisheries. Springer, Cham. pp. 117-132 https://doi.org/10.1007/978-3-319-17034-3_7

Plummer M. 2015. JAGS Version 4.0.0 user manual 0-42.

Pronk R., Wilson D.R., Harcourt R. 2010. Video playback demonstrates episodic personality in the gloomy octopus. J Exp Biol. 213: 1035-1041. https://doi.org/10.1242/jeb.040675

R Core Team. 2020. R: A Language and Environment for Statistical Computing.

Sauer W.H.H., Gleadall I.G., Downey-Breedt N., et al. 2020. World Octopus Fisheries. Rev. Fish. Sci. Aquacult. https://doi.org/10.1080/23308249.2019.1680603

Sillero-Rios J., Sureda A., Capó X., et al. 2018. Biomarkers of physiological responses of Octopus vulgaris to different coastal environments in the western Mediterranean Sea. Mar. Pol. Bul. 128: 240-247. https://doi.org/10.1016/j.marpolbul.2018.01.032

Sinn D.L., Perrin N.A., Mather J.A., et al. 2001. Early temperamental traits in an octopus (Octopus bimaculoides). J.Comp. Psychol. 115: 351. https://doi.org/10.1037/0735-7036.115.4.351

Su Y.-S., Yajima M. 2015. R2jags: Using R to Run 'JAGS'. R package version $0.5-7$. Available: https://cran.r-project.org/web/packages/R2jags/index.html

Uusi-Heikkilä S., Wolter C., Klefoth T., et al. 2008. A behavioral perspective on fishing-induced evolution. Trends Ecol. Evol. 23: 419-421. https://doi.org/10.1016/j.tree 2008.04.006

Van Buskirk J. 2002. A comparative test of the adaptive plasticity hypothesis: relationships between habitat and phenotype in anuran larvae. The Am. Natur. 160: 87-102. https://doi.org/10.1086/340599

\section{SUPPLEMENTARY MATERIAL}

The following supplementary material is available through the online version of this article and at the following link: http:// scimar.icm.csic.es/scimar/supplm/sm05065esm.pdf

Fig. S1. - Distribution of the Octopus score "posteriors" to first capture (see Eq. 1). The red dot shows the median (or percentile $50 \%$ ); the whiskers are the $95 \%$ Bayesian confidence interval (BCI; percentiles 2.5 and $97.5 \%$ ).

Table S1 - Distribution of the main parameters "posteriors" on estimated repeatability and mean latency to first capture (see Eq. 1): the median (or percentile 50\%), 95\% Bayesian confidence interval (BCI; percentiles 2.5 and $97.5 \%$ ), the convergence index of the chains (at convergence, Rhat=1) and the number of effective iterations (n.eff).

Table S2. - Results from the Pearson's correlation analyses of recorded behaviour and body patterns of $\mathrm{O}$. vulgaris facing a bait trap. A, arm exploration; B, body exploration; C, crawl; $\mathrm{D}$, defence position; $\mathrm{E}$, pulling the trap; $\mathrm{F}$, approaching the trap; G, grabbing the trap; $\mathrm{H}$, retreat; I, resting in the den; J, jet swim; Y, capture bait/prey; M, broad mottle skin; N, hood/striped skin pattern; O, passing cloud skin pattern; R, regular skin pattern; S, smooth texture; $\mathrm{Z}$, dark skin pattern. (For detailed definitions see Table 1). 
Scientia Marina 85(1)

March 2021, S1-S3, Barcelona (Spain)

ISSN-L: 0214-8358

\section{Behaviour and body patterns of Octopus vulgaris facing a baited trap: first-capture assessment}

Marta Dominguez-Lopez, Guillermo Follana-Berná, Pablo Arechavala-Lopez

Supplementary material 


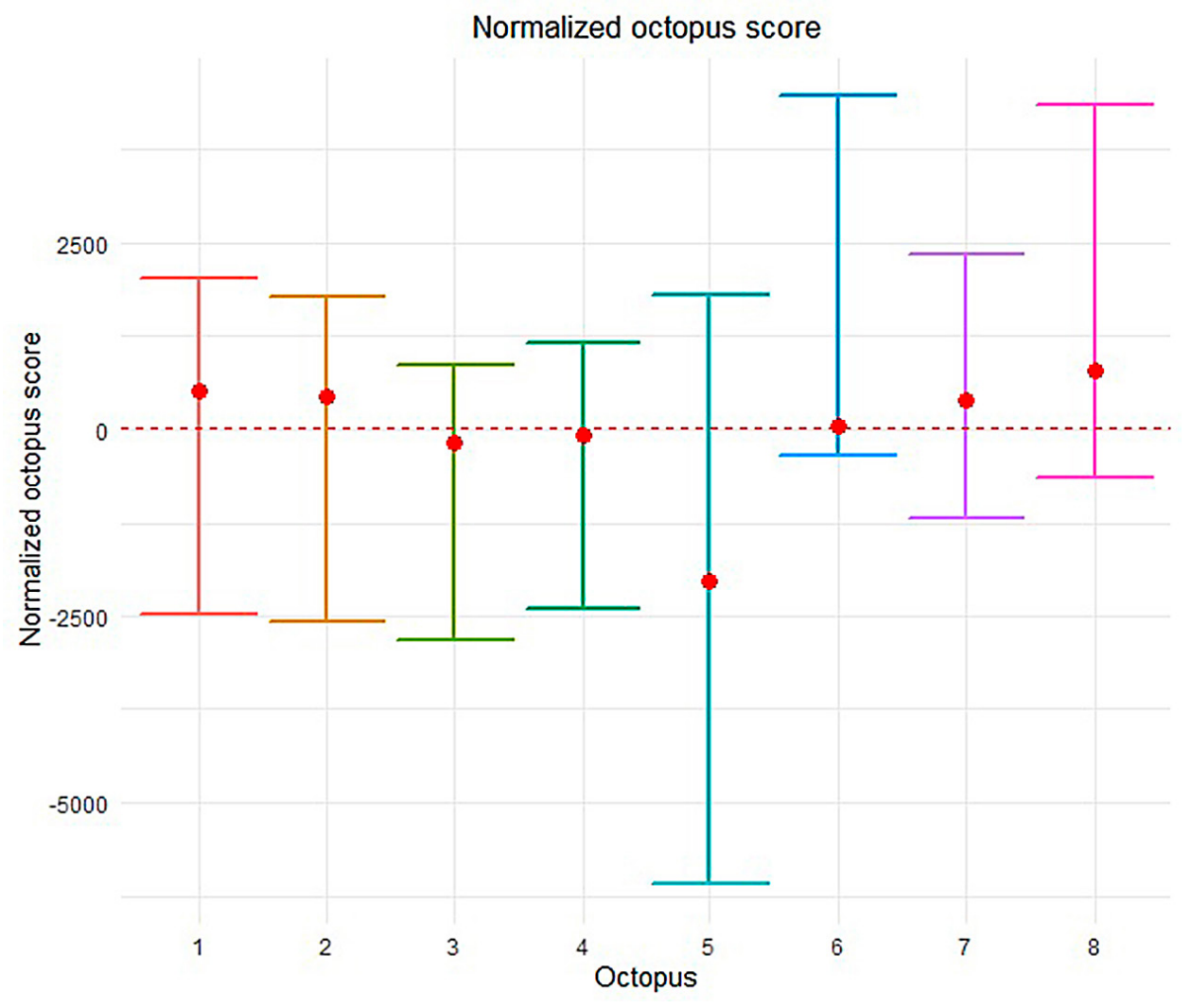

Fig. S1. - Distribution of the Octopus score "posteriors" to first capture (see Eq. 1). The red dot shows the median (or percentile 50\%); the whiskers are the $95 \%$ Bayesian confidence interval (BCI; percentiles 2.5 and $97.5 \%$ )

Table S1. - Distribution of the main parameters "posteriors" on estimated repeatability and mean latency to first capture (see Eq. 1): the median (or percentile 50\%), 95\% Bayesian confidence interval (BCI; percentiles 2.5 and $97.5 \%$ ), the convergence index of the chains (at convergence, Rhat $=1$ ) and the number of effective iterations (n.eff).

\begin{tabular}{cccccccc}
\hline & $2.50 \%$ & $25 \%$ & $50 \%$ & $75 \%$ & $97.50 \%$ & Rhat & n.eff \\
\hline Repeatability & $<0.001$ & $<0.001$ & $<0.001$ & 0.029 & 0.559 & 1.004 & 620 \\
Octopus 1 & -2477.432 & -16.687 & 513.541 & 986.594 & 2017.020 & 1.003 & 1500 \\
Octopus 2 & -2574.675 & -35.572 & 436.959 & 856.278 & 1782.190 & 1.003 & 1700 \\
Octopus 3 & -2837.730 & -333.949 & -167.014 & -41.049 & 866.633 & 1.003 & 3100 \\
Octopus 4 & -2409.246 & -154.915 & -69.016 & -5.822 & 1156.142 & 1.003 & 5100 \\
Octopus 5 & -6075.179 & -3329.496 & -2039.848 & -794.734 & 1802.079 & 1.001 & 14000 \\
Octopus 6 & -348.656 & 17.923 & 60.810 & 281.445 & 4448.723 & 1.004 & 1100 \\
Octopus 7 & -1192.027 & 91.441 & 392.459 & 720.282 & 2344.410 & 1.002 & 18000 \\
Octopus 8 & -632.232 & 315.390 & 779.758 & 1352.644 & 4329.980 & 1.001 & 4200 \\
Tolerance octopus & -2210.813 & -516.599 & 160.223 & 828.004 & 2643.139 & 1.001 & 30000 \\
Tolerance residuals & -2024.799 & -11.587 & -0.032 & 3.466 & 989.701 & 1.002 & 30000 \\
Tolerance Test & -2489.067 & -777.530 & -110.128 & 570.125 & 2394.589 & 1.002 & 19000 \\
Deviance & -3247.945 & -1697.596 & -1015.347 & -359.768 & 1106.147 & 1.001 & 15000 \\
\hline
\end{tabular}


Table S2. - Results from the Pearson's correlation analyses of recorded behaviour and body patterns of $O$. vulgaris facing a bait trap. A, arm exploration; B, body exploration; C, crawl; D, defence position; E, pulling the trap; F, approaching the trap; G, grabbing the trap; H, retreat; I, resting in the den; J, jet swim; Y, capture bait/prey; M, broad mottle skin; $\mathrm{N}$, hood/striped skin pattern; $\mathrm{O}$, passing cloud skin pattern; R, regular skin pattern; S, smooth texture; Z, dark skin pattern. (For detailed definitions see Table 1.)

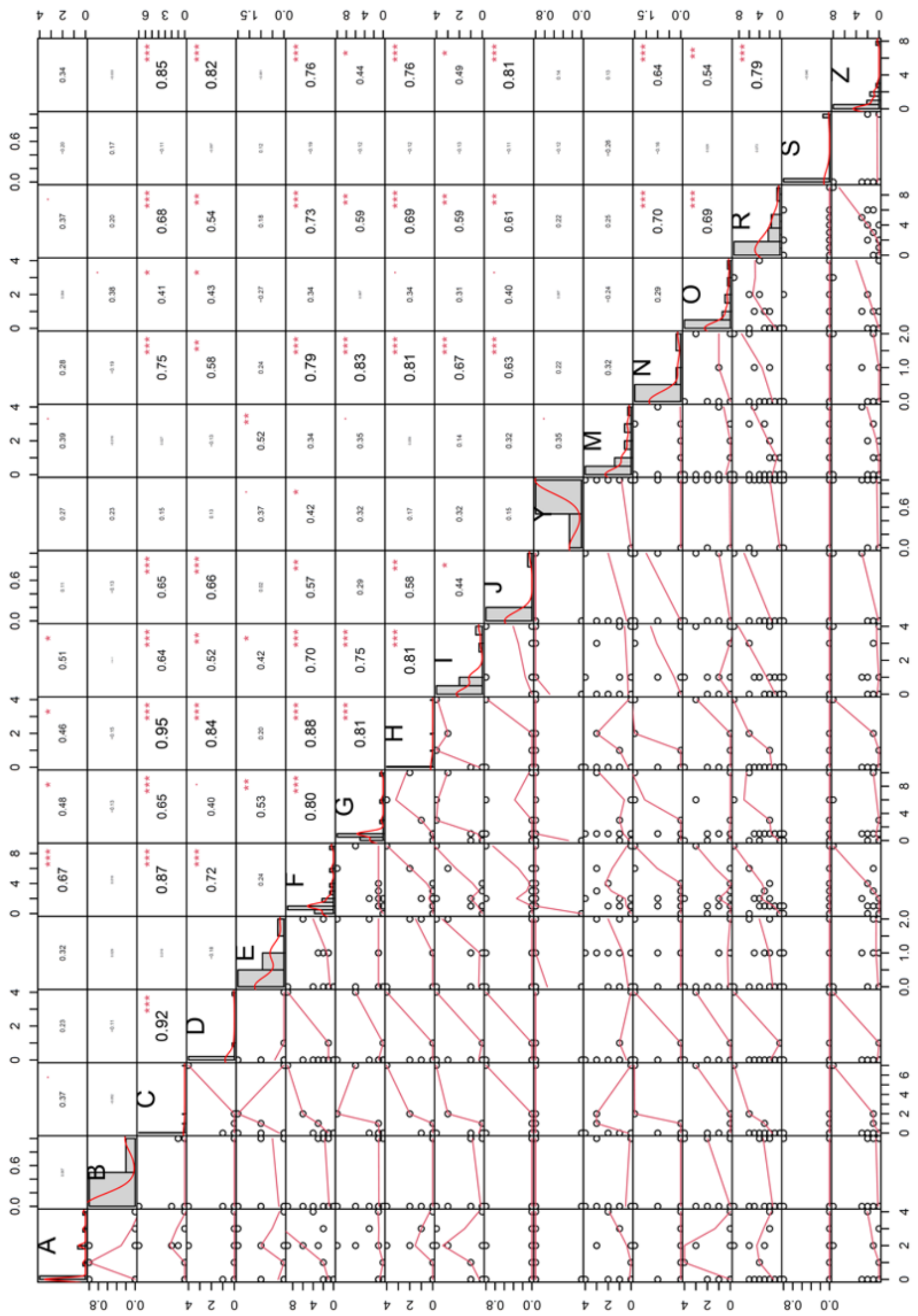

